\title{
SIMULASI DAN ANALISA SCHEDULING SERVICE CLASS PADA JARINGAN WIMAX MENGGUNAKAN OPNET MODELER
}

\author{
Ahmad Arif, Helmy Fitriawan, Muhamad Komarudin \\ Jurusan Teknik Elektro, Fakultas Teknik, Universitas Lampung \\ imailisia@gmail.com
}

\begin{abstract}
Abstrak
Kebutuhan manusia akan informasi saat ini mendorong permintaan terhadap akses data internet bekecepatan tinggi meningkat dengan pesatnya. Layanan yang ditawarkan pun semakin beragam mencakup teks, suara, video, dan data. Hal tersebut kini telah semakin menjadi kebutuhan sehari-hari yang tak dapat dipisahkan dari kehidupan manusia. Sehingga dibutuhkan teknologi yang mampu memberikan layanan suara, data, maupun video dengan kualitas yang lebih baik. Penelitian ini membahas tentang penerapan scheduling service class pada aplikasi-aplikasi komunikasi data pada jaringan fixed WiMAX. Jaringan fixed WiMAX disimulasikan menggunakan Opnet Modeler. Perancangan jaringan dilakukan menggunakan satu buah BS, 16 buah SS, dan server sebagai sumber trafik. Pengambilan data dilakukan selama sepuluh menit. Hasil simulasi yang didapat menunjukkan bahwa pada aplikasi suara, service class UGS memiliki nilai throughput terbesar yaitu 3 Mbps dan memiliki nilai jitter terkecil yaitu mendekati 0 s. Pada aplikasi video, service class rtPS memiliki nilai throughput terbesar yaitu 44 Mbps dan memiliki nilai delay terkecil yaitu 0,17 s. Pada aplikasi file transfer, service class nrtPS memiliki nilai throughput terbesar yaitu 6.745 .187 bps dan memiliki nilai delay terkecil yaitu 0,014 s. Pada aplikasi web browsing, service class nrtPS memiliki nilai throughput terbesar yaitu 8,2 Mbps dan memiliki nilai delay terkecil yaitu 0,022 s.
\end{abstract}

Kata kunci : fixed WiMAX, scheduling service, Opnet Modeler

\begin{abstract}
Human need for information now pushing the demand for internet data access speed high rises rapidly. The service offers diverse include text, sound, video, and data. It has become even daily needs that can not be separated from human life. So the need for technology that can deliver voice, data, and video with better quality. This study discusses the application of scheduling service class on data communications applications in the Fixed WiMAX network. Fixed WiMAX network is simulated using OPNET Modeler. Network design performed using a single BS, SS 16 pieces, and the server as a source of traffic. Data is collected for ten minutes. The simulation results obtained show that the application of sound, UGS service class has the greatest value is 3 Mbps throughput and jitter smallest value that is close to 0 s. In video applications, rtPS service class has the greatest value of throughput is 44 Mbps and has the smallest delay value was 0.17 s. On the application file transfer, nrtPS service class has the greatest value is 6,745,187 bps throughput and has the smallest delay value is 0.014 s. In the web browsing application, nrtPS service class has the greatest value is 8.2 Mbps throughput and has the smallest delay value is $0.022 \mathrm{~s}$.
\end{abstract}

Keywords : fixed WiMAX, scheduling service, Opnet Modeler

\section{Pendahuluan}

Perkembangan layanan informasi komunikasi melaju begitu pesat. Pada awalnya layanan informasi komunikasi hanya berupa suara, sekarang telah berkembang layanan yang dapat memenuhi kebutuhan informasi, data (multimedia), dan video. Pada layanan informasi data (multimedia) dan video, kecepatan dan kehandalan dalam pengaksesan data maupun video merupakan parameter penting bagi pelanggan. Komunikasi video juga membutuhkan lebar pita yang besar karena melibatkan transmisi suara dan data real time. Sehingga dibutuhkan teknologi yang mampu memberikan layanan suara, data, maupun video dengan kualitas yang lebih baik.

Teknologi yang digunakan sekarang masih berupa tradisional broadband yang dilewatkan melalui saluran telepon dan kabel yang perkembangannya lambatkarena masalah pemasangan,pengembangan, dan pembangunan infrastruktur yang mahal dan terbatas. Hadirnya teknologi WiMAX dengan standar IEEE 802.16 
memungkinkan koneksi nirkabel kecepatan tinggi dengan biaya yang efektif ke pengguna, baik yang berada di perkotaan maupun daerah. [1]

Teknologi Worldwide Interoperability for Microwave Access (WiMAX) merupakan teknologi yang masih baru dalam kelurga jaringan komputer, namun WiMAX merupakan salah satu teknologi broadband wireless connection yangg saat ini banyak operator di Indonesia mulai tertarik untuk mengimplementasikan. Teknologi WiMAX mengacu pada standar 802.16 dikembangkan oleh Institute of Electrical and Electronics Engineers (IEEE), dapat memberikan perspektif baru dalam mengakses internet dengan kecepatan tinggi tanpa tergantung pada jaringan kabel. Dengan lahirnya teknologi baru di jaringan wireless seperti WiMAX, tentunya diiringi dengan kemampuan yang lebih bila dibanding dengan teknologi generasi sebelumnya. Disamping mengusung isu interoperability, security, availability, capability, Non Line of Sight (NLOS), jarak jangkau yang luas dan mobility, WiMAX tak kalah penting juga menawarkan Quality of Service (QoS). Pengaturan QoS pada jaringan WiMAX dijalankan oleh Medium Access Control (MAC) layer.

QoS adalah kemampuan dari suatu jaringan untuk menyediakan pelayanan yang berbeda sesuai dengan kebutuhan pengguna WiMAX. Dengan kemampuan memberikan QoS yang beragam, maka akan sangat menguntungkan baik bagi operator maupun pelanggan. Bagi operator dapat memberikan perbedaan layanan dan tarif berdasarkan tipe QoS kepada yang diberikan pelanggan. Sedangkan pada pelanggan dapat memilih layanan sesuai dengan pertimbangan kebutuhan.

Tujuan dari penelitian ini adalah mengetahui penerapan scheduling service class pada aplikasiaplikasi komunikasi data pada jaringan WiMAX dengan mensimulasikan sebuah jaringan WiMAX menggunakan software OPNET Modeler. Serta mencoba menganalisa jenis scheduling service class manakah yang tepat untuk diimplementasikan pada jaringan, sehingga jaringan tersebut dapat berjalan dengan baik.

\section{Tinjauan Pustaka}

\subsection{Standarisasi WiMAX}

WiMAX merupakan standar Broadband Wireless Access (BWA) dengan kemampuan untuk menyalurkan data kecepatan tinggi (layaknya teknologi xDSL pada jaringan wireline). Banyak kemampuan lebih yang ditawarkan oleh teknologi WiMAX dibanding teknologi sebelumnya seperti kemampuan diterapkan dalam kondisi Non Line of Sight (NLOS), aplikasinya baik untuk fixed, nomadix, portable maupun mobile.

Di IEEE terdapat working group yang khusus menangani dan mengembangkan WIMAX (802.16).
Standar 802.16 ini difokuskan untuk mengatur spesifikasi sistem WiMAX di layer MAC (layer 2) dan PHY (layer 1). Di ETSI (European Telecommunications Standard Institute) juga mengatur spesifikasi BWA yang setara dengan WiMAX yaitu ETSI BRAN HIPERACCESS. Standar ini mengatur spesifkasi fixed point to Multipoint (PMP) BWA yang beroperasi pada band frekuensi 10 sampai dengan $66 \mathrm{GHz}$ [2]. Standarisasi untuk WiMAX sendiri terus mengalami evolusi dan pengembangan oleh IEEE sejak pertama kali dikeluarkan tahun 2001.

Tabel 1. Standarisasi WiMAX

\begin{tabular}{|c|c|c|c|}
\hline & 802.16 & $\begin{array}{l}802.16 a \\
\text { rev d }\end{array}$ & $802.16 \mathrm{e}$ \\
\hline Selesai & $\begin{array}{l}\text { Desember } \\
2001\end{array}$ & Juni 2004 & $\begin{array}{l}\text { Akhir } \\
2005\end{array}$ \\
\hline Spektrum & $\begin{array}{l}10-66 \\
\mathrm{GHz}\end{array}$ & $2-11 \mathrm{GHz}$ & $<6 \mathrm{GHz}$ \\
\hline $\begin{array}{l}\text { Kondisi } \\
\text { kanal }\end{array}$ & LOS & NLOS & NLOS \\
\hline Bit Rate & $\begin{array}{l}32-134 \\
\text { Mbps pada } \\
28 \mathrm{MHz}\end{array}$ & $\begin{array}{l}\text { Sampai } 70 \\
\text { Mbps }\end{array}$ & $\begin{array}{l}\text { Sampai } 35 \\
\text { MHz }\end{array}$ \\
\hline Modulasi & $\begin{array}{l}\text { QPSK, } \\
\text { 16QAM, } \\
\text { 64QAM }\end{array}$ & $\begin{array}{l}\text { OFDM } 256 \\
\text { subcarrier, } \\
\text { QPSK, } \\
\text { 16QAM, } \\
\text { 64QAM }\end{array}$ & $\begin{array}{l}\text { OFDM } \\
256 \\
\text { subcarrier, } \\
\text { QPSK, } \\
\text { 16QAM, } \\
\text { 64QAM }\end{array}$ \\
\hline Mobilitas & Fixed & $\begin{array}{l}\text { Fixed, } \\
\text { portable }\end{array}$ & $\begin{array}{l}\text { Nomadic, } \\
\text { portable }\end{array}$ \\
\hline Bandwidth & $\begin{array}{l}20,25,28 \\
\mathrm{MHz}\end{array}$ & $\begin{array}{l}1,5 \text { sampai } \\
20 \mathrm{MHz}\end{array}$ & $\begin{array}{l}1,25 \\
\text { sampai } 20 \\
\mathrm{MHz}\end{array}$ \\
\hline Jangkauan & $2-5 \mathrm{Km}$ & $\begin{array}{l}\text { Hingga } 30 \\
\mathrm{Km}\end{array}$ & $\begin{array}{l}\text { Hingga } 10 \\
\mathrm{Km}\end{array}$ \\
\hline
\end{tabular}

\subsection{Struktur Layer}

Karakteristik standar 802.16e ditentukan oleh spesifikasi teknis dari Physical Layer (PHY Layer) dan Medium Access Control (MAC). Perbedaan karakteristik kedua layer ini akan membedakan varian-variannya. Pada gambar 3. ditunjukkan lingkup dari standar yang meliputi PHY dan MAC.

Physical Layer menjalankan fungsi mengalirkan data di level fisik. MAC Layer berfungsi sebagai penerjemah protokol - protokol yang ada di atasnya seperti ATM dan IP. MAC Layer dibagi menjadi tiga sub-layer yaitu : Convergence Sublayer (CS), MAC Common Part Sublayer dan Security Sublayer [3]. Fungsi lapis fisik adalah membangun koneksi fisik diantara dua sisi alat komunikasi, dan biasanya melalui dua jalur komunikasi (uplink dan downlink). 


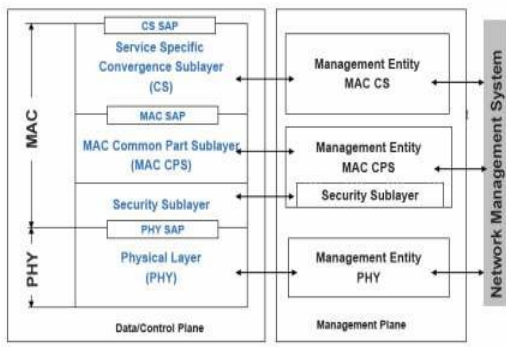

Gambar 1. Layer PHY dan MAC pada Standar WiMAX

\section{Scheduling Service Class}

Pada mekanisme MAC layer memungkinkan WiMAX dapat menjalankan QoS dengan berbagai kebutuhan bandwidth dan aplikasi. Sebagai contoh aplikasi suara dan video memerlukan latency yang rendah tetapi masih bisa mentolerir beberapa error rate. Sebaliknya aplikasi-aplikasi data pada umumnya sangat sensitif terhadap error rate, sedangkan faktor latency bukan menjadi pertimbangan kritis.

Perubahan parameter QoS bisa diminta oleh SS ke BS dengan sambungan masih tetap terjaga. Pada layer MAC menggunakan scheduling service class untuk mengirimkan dan menangani SDU dan MAC PDU berdasarkan QoS yang diinginkan. Berikut jenis dari schedulling service pada WiMAX [4].

1) Unsolicited Grant Service (UGS)

UGS digunakan untuk layanan yang membutuhkan jaminan pengiriman data dengan prioritas paling utama. Karakteristik UGS meliputi

a. Seperti halnya layanan Constant Bit Rate (CBR) pada ATM, yang dapat memberikan pengiriman data secara periodik dengan ukuran yang sama.

b. Untuk layanan yang membutuhkan jaminan real-time.

c. Efektif untuk layanan yang sensitif terhadap throughput, latency dan jitter.

d. Maximum dan minimum bandwidth yang ditawarkan sama.

e. Contohnya untuk aplikasi VoIP, T1/E1 atau ATM CBR.

2) Real-time Polling Service (rtPS)

Karakteristik dari rtPS meliputi :

a. efektif untuk layanan yang sensitif terhadap throughput dan latency.

b. Garansi rate dan syarat delay telah ditentukan.

c. Contohnya MPEG, Voip, Video Conference

3) non-real-time Polling Service (nrtPS)

Karakteristik dari nrtPS meliputi : a. efektif untuk aplikasi yang membutuhkan throughput yang intensif.

b. Layanan mungkin dapat di expand sampai full bandwidth namun dibatasi pada kecepatan maksimum yang telah ditentukan.

c. Garansi rate diperlukan namun delay tidak digaransi.

d. Contohnya aplikasi seperti video dan audio streaming.

4) Best Effort (BE)

Karakteristik dari BE meliputi :

a. Untuk trafik yang tidak membutuhkan jaminan kecepatan data.

b. Tidak ada jaminan pada rate atau delaynya.

c. Contohnya aplikasi internet (web browsing), email, FTP.

\section{OPNET Modeler}

OPNET Modeler adalah sebuah perangkat lunak untuk memodelkan dan mensimulasi jaringan kabel maupun jaringan nirkabel. OPNET menyediakan lingkungan kerja yang luas untuk pemodelan dan evaluasi kehandalan berbagai jaringan komunikasi. Perangkat lunak Opnet yang digunakan pada penelitian ini adalah Opnet Modeler versi 14.0

Model jaringan WiMAX merupakan model simulasi kejadian diskrit (Discrete Event Simulation Model) yang memungkinkan untuk melakukan penganalisaan performansi jaringan Wireless Metropolitan Area Network [5].

\section{Simulasi Jaringan}

Pembuatan simulasi menggunakan beberapa buah node yang berbeda sesuai dengan fungsinya pada jaringan. Secara umum, jaringan fixed Wimax yang akan dibuat terdiri dari beberapa Subscriber Station (SS), satu Base Station (BS), dan server. SS diwakili oleh Node WiMAX workstation, node Wimax_bs_router mewakili BS WiMAX sedangkan server diwakili oleh node ethernet_server. Program akan dijalankan untuk mensimulasikan aktivitas jaringan Wimax selama 10 menit (600 detik).

\subsection{Pengaturan Aplikasi Data}

Aplikasi data adalah jenis-jenis data yang akan dilewatkan sebagai trafik pada jaringan Wimax. Ada 4 jenis aplikasi data yang akan digunakan pada simulasi ini, yaitu suara, video, FTP dan web browsing.

1) Aplikasi suara

Sebuah aplikasi suara memungkinkan dua klien untuk membangun saluran virtual dimana mereka dapat berkomunikasi menggunakan sinyal suara 
yang telah dikodekan secara digital. Pengaturan aplikasi suara dapat dilakukan sesuai tabel 2 .

Tabel 2. Parameter pada aplikasi suara

\begin{tabular}{|l|l|}
\hline \multicolumn{1}{|c|}{ Parameter } & \multicolumn{1}{c|}{ Nilai } \\
\hline Encoder scheme & G.711 \\
\hline Voice frame per packet & 1 \\
\hline Type of Service & Interactive voice (6) \\
\hline
\end{tabular}

Aplikasi suara yang digunakan adalah PCM quality Speech dimana spesifikasinya memakai skema encoder G. 711 dengan bit rate sebesar $64 \mathrm{Kbps}$. Selain itu voice frame per paket yang digunakan sebesar 1 frame per paket. Sedangkan Type of Service $(T o S)$ diatur menggunakan Interactive voice (6).

\section{2) Aplikasi Video}

Aplikasi video yang digunakan pada simulasi ini adalah aplikasi video konferensi. Sebuah aplikasi video konferensi memungkinkan pengguna untuk mentransfer frame streaming video pada jaringan. Parameter video pada simulasi kali ini menggunakan video low resolution yaitu Frame waktu antar kedatangan sebesar 10 frame per detik, dengan ukuran frame $128 \times 120$ pixels. Sedangkan Type of Service (ToS) yang digunakan adalah Best Effort (0). Parameter aplikasi video dapat dilihat pada tabel 3.

Tabel 3. Parameter pada aplikasi Video

\begin{tabular}{|l|l|}
\hline \multicolumn{1}{|c|}{ Parameter } & \multicolumn{1}{c|}{ Nilai } \\
\hline Frame interarrival time & 15 frame/sec \\
\hline Frame size information (bytes) & $128 \times 240$ pixels \\
\hline Type of service & Best effort $(0)$ \\
\hline
\end{tabular}

\section{3) Aplikasi FTP}

Aplikasi FTP memungkinkan transfer file antara klien dan server. FTP memiliki dua perintah dasar untuk memindahkan file yaitu perintah "get" dan "put". Perintah "get" memicu pengiriman file dari server ke klien. Perintah "put" mengirim file dari klien ke server.

Tabel 4. Parameter pada aplikasi FTP

\begin{tabular}{|l|l|}
\hline \multicolumn{1}{|c|}{ Parameter } & \multicolumn{1}{c|}{ Nilai } \\
\hline Command mix (get/total) & $50 \%$ \\
\hline Inter-request time (s) & constant $(1,0)$ \\
\hline File size (bytes) & Constant (50000) \\
\hline Type of service & Excellent effort (3) \\
\hline
\end{tabular}

Aplikasi FTP yang digunakan pada simulasi ini menggunakan data yang memiliki ukuran file sebesar 50.000 byte dan inter-request time menggunakan constant $(1,0)$.

Command Mix pada pengaturan aplikasi FTP menunjukkan prosentase file perintah "get" terhadap perintah FTP total. Sedang prosentase sisanya adalah besarnya file dari perintah "put". Dengan kata lain saat command mix diatur sebesar $50 \%$ maka besarnya file yang dikirim dan yang diterima sama. Type of Service yang digunakan untuk aplikasi ini adalah Excellent effort (3).

\section{4) Aplikasi Web browsing}

Model aplikasi Web browsing adalah HTTP. Pengguna mengunduh halaman dari server. Halaman yang diunduh ini berisi data teks dan informasi grafis. Data yang digunakan sesuai dengan nilai parameter seperti tabel 5 .

Tabel 5. Parameter pada aplikasi HTTP

\begin{tabular}{|c|c|}
\hline Parameter & Nilai \\
\hline $\begin{array}{l}\text { HTTP } \\
\text { Specification }\end{array}$ & HTTP 1.1 \\
\hline $\begin{array}{l}\text { Page interarrival } \\
\text { time }\end{array}$ & Constant $(1,0)$ \\
\hline Page properties & - \\
\hline Object size & $\begin{array}{llr}\text { Konstan } & (1000), & \begin{array}{l}\text { large } \\
\text { image, }\end{array} \\
\text { image }\end{array}$ \\
\hline $\begin{array}{l}\text { Number of } \\
\text { object }\end{array}$ & $\begin{array}{l}\text { Konstan (1), konstan (5), } \\
\text { konstan (8), konstan (3) }\end{array}$ \\
\hline Server selection & - \\
\hline $\begin{array}{ll}\begin{array}{l}\text { Page } \\
\text { server }\end{array} & \text { per } \\
\end{array}$ & Exponential (10) \\
\hline Type of service & BE (Best Effort) \\
\hline
\end{tabular}

Spesifikasi HTTP yang digunakan adalah HTTP versi 1.1. Page interarrival time pareto $(5,20)$. Parameter page properties menunjukkan properti halaman yang dijalankan pada aplikasi HTTP. Berdasarkan tabel 5. di atas, suatu web yang dimodelkan memiliki halaman web dengan ukuran 1000 byte dan berisi obyek berupa large image sejumlah 5 buah, medium image sebanyak 3 buah, dan small image sebanyak 8 buah.

\subsection{Skenario Simulasi}

Pada simulasi ini akan dirancang 4 skenario, dengan masing-masing skenario menggunakan trafik yang sama, dan menggunakan jenis scheduling service class yang berbeda. Dimana pada masingmasing skenario terdiri dari 4 jenis scheduling service class, yaitu UGS, rtPS, nrtPS, dan BE. Untuk seluruh skenario akan menggunakan model jaringan yang terdiri dari 1 server, 1 base station, dan 16 subscriber station. Sebuah server yang menyediakan layanan aplikasi akan terhubung dengan base station. Base station akan memancarkan sinyal yang kemudian akan terkirim kepada subscriber station di sekitar base station, proses ini disebut downlink. 
Untuk seluruh skenario akan menggunakan konfigurasi aplikasi maksimal untuk setiap aplikasi yang sudah tersedia pada OPNET. Sehingga performa setiap QoS teruji dalam menangani aplikasi dengan konfigurasi maksimal dan agar dapat menentukan jenis scheduling service class terbaik untuk masing-masing aplikasi dengan konfigurasi maksimal. Berikut beberapa skenario yang akan dilakukan :

\section{1) Voice Traffic}

Pada skenario ini akan menguji performa masing-masing scheduling service class dalam menangani Voice Traffic dengan menggunakan UGS, rtPS, dan Be. Server akan menyediakan aplikasi voice dengan kualitas PCM Quality Service. Aplikasi yang dilayani oleh base station adalah voice, sesuai dengan apa yang sudah disediakan oleh server. subscriber station yang digunakan sebanyak 16 buah, dimana seluruh subscriber station meminta satu aplikasi yang sama, yaitu voice.

\section{2) Video Conferencing Traffic}

Pada skenario ini akan menguji performa masing-masing scheduling service class dalam menangani Video Conferencing Traffic dengan menggunakan UGS, rtPS, dan BE. Server akan menyediakan aplikasi video conferenecing dengan resolusi rendah. Aplikasi yang dilayani oleh base station adalah video Conference, sesuai dengan apa yang sudah disediakan oleh server. subscriber station yang digunakan sebanyak 16, dimana seluruh subscriber station meminta satu aplikasi yang sama, yaitu video conference.

\section{3) File Transfer Traffic}

Pada skenario ini akan menguji performa masing-masing scheduling service class dalam menangani file transfer Traffic dengan menggunakan UGS, nrtPS dan BE. Server akan menyediakan aplikasi file transfer. Aplikasi yang dilayani oleh base station adalah file transfer, sesuai dengan apa yang sudah disediakan oleh server. subscriber station yang digunakan sebanyak 16 buah, dimana seluruh subscriber station meminta satu aplikasi yang sama, yaitu file transfer.

\section{4) Web Browsing Traffic}

Pada skenario ini akan menguji performa masing-masing scheduling service class dalam menangani Web Browsing Traffic dengan menggunakan UGS, nrtPS, dan BE. Server akan menyediakan aplikasi web browsing. Aplikasi yang dilayani oleh base station adalah web browsing, sesuai dengan apa yang sudah disediakan oleh server. subscriber station yang digunakan sebanyak 16 buah, dimana seluruh subscriber station meminta satu aplikasi yang sama, yaitu web browsing.

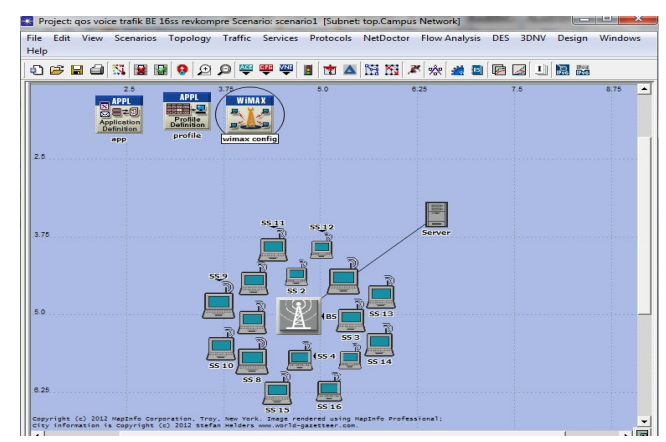

Gambar 2. Topologi jaringan fisik simulasi

\section{Analisa Hasil Simulasi Jaringan}

Perbandingan hasil simulasi dilakukan dengan membandingkan hasil simulasi yang diperoleh pada jenis aplikasi yang digunakan dengan jenis scheduling service class yang digunakan.

\subsection{Voice Traffic}

\section{Throughput}

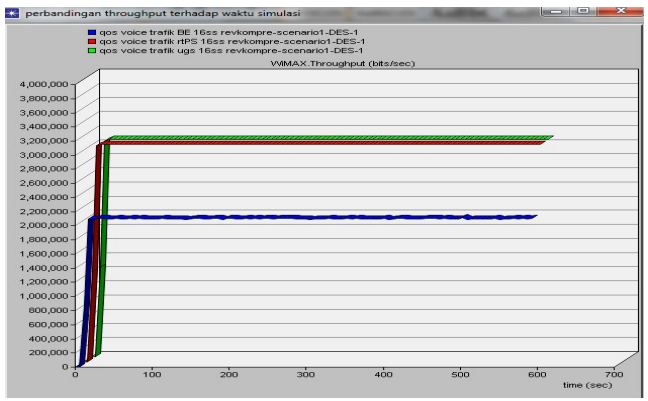

Gambar 3. Perbandingan nilai throughput pada UGS, rtPS, dan BE

Berdasarkan grafik diatas dapat kita lihat nilai throughput pada masing-masing layanan, dimana UGS memiliki nilai yang tinggi yang hampir sama dengan rtPS yaitu dengan nilai sebesar 3 Mbps, serta BE memiliki nilai throughput sebesar 2 Mbps.

Jitter

Berdasarkan grafik dibawah dapat kita lihat bahwa pada layanan BE memiliki nilai jitter tertinggi daripada UGS dan rtPS, dengan nilai rataratanya 2 ms. Pada layanan UGS dan rtPS memiliki nilai jitter yang hampir sama. 


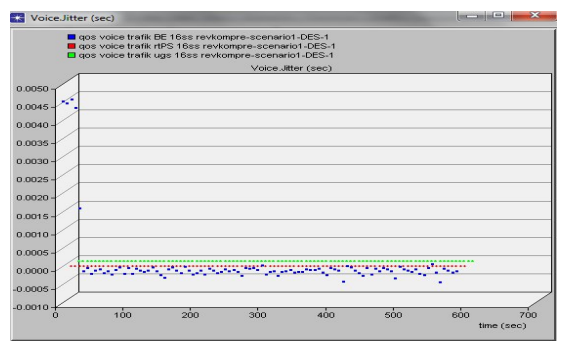

Gambar 4. Perbandingan nilai jitter pada UGS, rtPS, dan BE

\subsection{Video conference Traffic}

\section{Throughput}

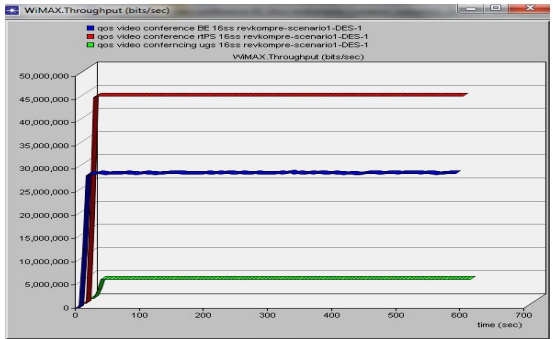

Gambar 5. Perbandingan nilai throughput pada UGS, rtPS, dan BE

Berdasarkan grafik diatas, dapat kita lihat nilai throughput pada masing-masing layanan, dimana layanan rtPS memiliki nilai yang paling tinggi yaitu dengan nilai sebesar $44 \mathrm{Mbps}$, dan layanan BE memiliki nilai throughput sebesar 28 Mbps, serta layanan UGS memiliki nilai throughput sebesar 4 Mbps.

\section{Delay}

Pada gambar 6, layanan UGS memiliki nilai delay yang terbesar dibandingkan dengan layanan rtPS dan $\mathrm{BE}$, yaitu dengan nilai delay 4 detik. Hal ini dikarenakan pada layanan UGS menawarkan penggunaan untuk ukuran paket data tetap. Pada layanan BE memiliki nilai delay yang cukup relatif kecil, yaitu sebesar 0,27 detik. Dan pada layanan rtPS memiliki nilai delay yang terkecil yaitu sebesar 0,17 detik.

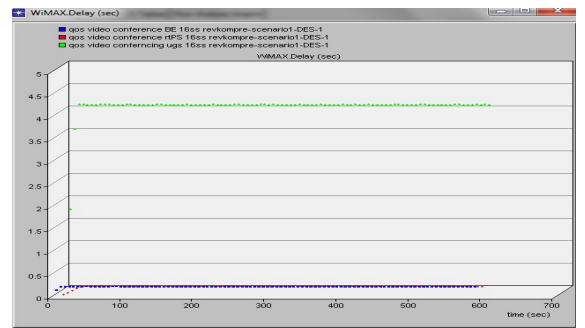

Gambar 6. Perbandingan nilai delay pada UGS, rtPS dan BE

\subsection{File Transfer Traffic}

\section{Throughput}

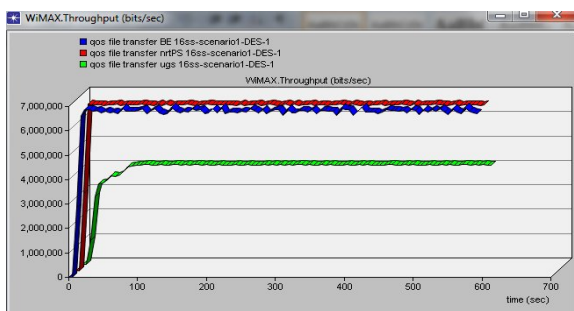

Gambar 7. Perbandingan nilai throughput pada UGS, nrtPS, dan BE

Berdasarkan grafik diatas dapat kita lihat nilai throughput pada layanan BE dan nrtPS memiliki nilai rata-rata throughput yang hampir sama, yaitu untuk layanan BE memiliki nilai sebesar 6.743.346 bps, dan layanan nrtPS memiliki nilai sebesar 6.745 .187 bps. Sedangkan untuk layanan UGS memiliki nilai rata-rata throughput sebesar $3.975 .829 \mathrm{bps}$.

Delay

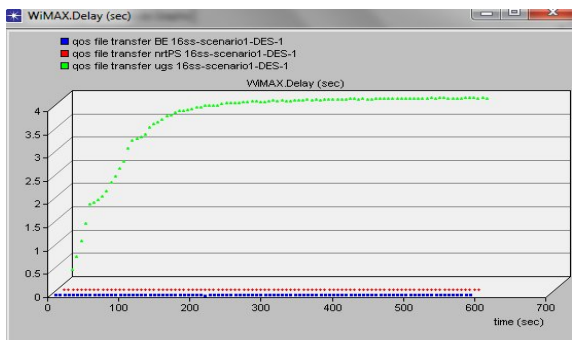

Gambar 8. Perbandingan nilai delay pada UGS, nrtPS, dan BE

Berdasarkan grafik diatas, pada layanan nrtPS memiliki nilai delay terkecil yaitu sebesar 0,014 detik. Layanan UGS memiliki nilai rata-rata delay terbesar yaitu sebesar 3,56 detik. Sedangkan pada layanan BE memiliki nilai delay sebesar 0,05 detik.

\subsection{Web Browsing Traffic}

throughput

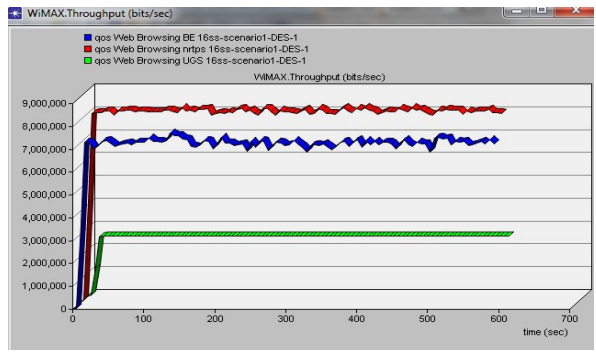

Gambar 9. Perbandingan nilai throughput pada UGS, nrtPS, dan BE 
Berdasarkan grafik diatas dapat kita lihat nilai throughput pada masing-masing layanan, dimana untuk layanan nrtPS memiliki nilai rata-rata throughput terbesar yaitu 8,2 Mbps, untuk layanan BE memiliki nilai rata-rata thtoughput sebesar 7,1 Mbps, sedangkan untuk layanan UGS memiliki nilai rata-rata throughput terkecil yaitu sebesar 2,5 Mbps. Delay

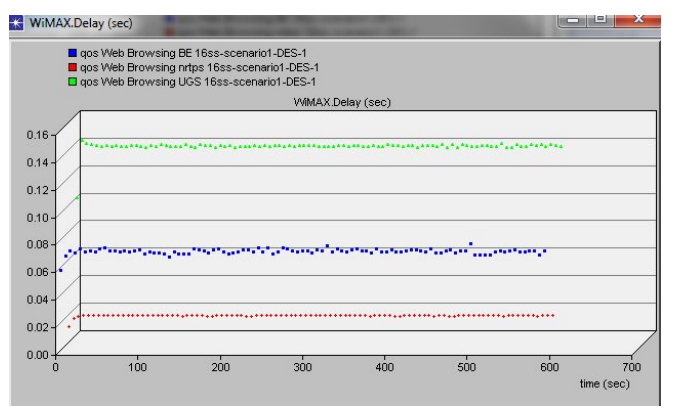

Gambar 10. Perbandingan nilai Delay pada UGS, rtPS, dan BE

Berdasarkan grafik diatas, pada layanan nrtPS memiliki nilai delay terkecil yaitu sebesar 0.022 detik. Layanan UGS memiliki nilai delay terbesar yaitu sebesar 0,14 detik. Sedangkan pada layanan BE memiliki nilai delay sebesar 0,075 detik.

\section{VII.Kesimpulan}

Berdasarkan hasil simulasi dan pembahasan yang telah dilakukan, maka dapat ditarik beberapa kesimpulan :

a. Pada aplikasi suara, nilai throughput tertinggi terdapat pada service class UGS, dan nilai jitter terendah terdapat pada service class UGS. Sehingga service class UGS lebih cocok digunakan pada aplikasi suara.

b. Pada aplikasi video, nilai throughput tertinggi terdapat pada service class rtPS, dan nilai delay terendah terdapat pada service class rtPS. Sehingga service class rtPS lebih cocok digunakan pada aplikasi video.

c. Pada aplikasi file transfer, service class nrtPS memiliki nilai throughput yang besar serta memiliki nilai delay yang kecil dibanding jenis service class yang lain. Sehingga service class nrtPS lebih cocok digunakan pada aplikasi file transfer.

d. Pada aplikasi web browsing, service class nrtPS memiliki nilai throughput yang besar serta memiliki nilai delay yang kecil dibanding jenis service class yang lain. Sehingga service class nrtPS lebih cocok digunakan pada aplikasi web browsing.

\section{Daftar Pustaka}

[1] Ricky Septiawan. 2009. Deregulasi WiFi (wireless Fidelity) dan WiMAX (Worldwide Interopability for Microwave Acces) di negara berkembang. Universitas Lampung.

[2] A. Syed and I. Mohammad. 2008. WiMax : Standards and Security. CRC Press. New York.

[3] Wibisono, Gunawan. dan Hantoro, Gunadi Dwi. 2006. WiMAX Teknologi Broadband Wireless Access (BWA) Kini dan Masa Depan. Informatika.

[4] Gunawan Wibisono, Gunadi Dwi Hantoro, Made Meganjaya, Yudi Pram. 2007. Peluang dan tantangan bisnis WiMAX di Indonesia. Informatika Bandung, Bandung.

[5] OPNET. Opnet Modeler 14.0 Documentation. 